\title{
ÁGUA DE MONTANHA: UM ESTUDO DE CASO NA FRANÇA SOBRE A RELAÇÃO ENTRE EMPRESA, TERRITÓRIO E PRODUTO
}

\author{
Larissa Bueno Ambrosini ${ }^{1}$, Georges Giraud ${ }^{2}$
}

\begin{abstract}
${ }^{1}$ Fundação Estadual de Pesquisa Agropecuária - Fepagro, Rua Gonçalves Dias, 570, Menino Deus, Porto Alegre, Brasil. Telefone: (51) 32888000. E-mail: larissabueno@gmail.com

${ }^{2}$ Institut National Supérieur Des Sciences Agronomiques, De L'alimentation Et De L'environnement - AgroSup Dijon, Boulevard Dr Petitjean,26, 21000, Dijon, França. Telefone: +33 3 80772525. E-mail: georges.giraud@agrosupdijon.fr.
\end{abstract}

\begin{abstract}
Resumo - As regiões montanhosas são consideradas áreas desfavorecidas do ponto de vista do desenvolvimento econômico, pois contam com baixa densidade populacional e fraca atividade industrial. Esse contexto contribuiu para que as fontes de água localizadas em montanhas tivessem menos contato com substâncias contaminantes e atividades poluidoras. A água proveniente dessas regiões é, assim, associada à pureza. A indústria de água envasada, um dos mercados mais dinâmicos do segmento de bebidas, vem tirando benefício da relação entre altitude e pureza. Considerando o território e a importância do recurso natural mencionado, propomos um estudo de caso com o objetivo de analisar a influência da relação empresaterritório no caso de usinas situadas em zonas de montanha, e que utilizam em seus produtos a denominação "água de fonte de montanha". Trata-se de um estudo de caso sobre um recurso natural importante o qual ainda é pouco abordado no meio acadêmico. Nossos resultados demonstram que a exploração de fontes em zonas de montanha auxilia a criar postos de trabalho localmente e contribui com a receita dos municípios onde as plantas industriais estão localizadas. Entretanto, trata-se de um produto cuja sustentabilidade em longo prazo é discutível.
\end{abstract}

Palavras-chave - Território. Montanha. Água de fonte de montanha.

Abstract - The mountains are considered as less favoured areas with a low population density and a weak industrial activity. This context contributed to the water sources located in mountain areas have had less contact with contaminants or potentially polluting activities. Thus, the water from these sources is related to the purity. The bottled water industry is taking advantage of this association between altitude and purity; it is the most dynamic market in the beverage industry currently. Considering the territory and the importance of the mentioned resource, we analyze the relationship between enterprise and territory of bottled water enterprises which using the name "mountain spring water", or images of mountains. It is a case study about an important natural resource in these areas and it escapes the classic studies of terroir products. Our study demonstrated that the exploitation of sources in mountain areas enables the creation of jobs locally and contributes to income generation in the municipalities. However, we must consider that bottled water is a product debatable in terms of environmental sustainability in the long term.

Keywords - Territory. Mountain. Mountain bottled water.

Recebido em: 22 de dezembro de 2015 Aprovado em: 31 de dezembro de 2015

\section{INTRODUÇÃO}

As montanhas têm um papel crucial no fornecimento de água doce, tanto em zonas de montanha, como em zonas de planície. Os grandes rios têm suas fontes situadas em terras altas, e mais da metade da humanidade depende da água doce que se acumula nas montanhas. O papel desse território no equilíbrio hídrico dos ecossistemas de seu entorno, entretanto, é mais complexo, pois as montanhas formam uma barreira para massas de ar obrigando-as a subir e originando precipitações nesse processo. As montanhas têm papel importante também na estocagem e distribuição de água para os vales. Em zonas úmidas, a proporção de água oriunda de zonas montanhosas pode perfazer $60 \%$ dos recursos totais de água doce disponíveis, enquanto que em zonas semiáridas ou áridas, essa proporção geralmente passa dos 90\% (LINIGER; WEINGARTNER, 1998). A água, portanto, é um recurso capital estreitamente ligado ao território de montanha.

Do ponto de vista do desenvolvimento, os territórios localizados em zonas de montanha são considerados 'desfavorecidos'. A natureza da topografia, tendo prejudicado o desenvolvimento de atividades industriais, a qualidade de suas nascentes de água pôde ser preservada.

Atualmente temos um contexto de consumo favorável à valorização de produtos saudáveis, de modos de vida e produção sustentáveis, de atividades que reconectem os homens à natureza. Assim, o que era tido como deficiência, pode ser trabalhado como vantagem. A imagem da montanha vem sendo utilizada justamente evocando pureza e preservação ambiental para valorizar diferentes produtos.

Considerando o território e sua forte relação com o recurso mencionado, propomos um estudo de caso com o objetivo de analisar a influência da relação empresaterritório, no caso das usinas que 'produzem' água 
envasada em zonas de montanha e utilizam em seus produtos a denominação "água de fonte de montanha", ou imagens de montanhas, e cujas fontes estejam situadas em zonas de montanha. Trata-se de um estudo de caso feito no França, país com terceiro maior nível de consumo do produto na Europa Ocidental - maior consumidor mundial de água envasada. A França tem também longa tradição na oferta de produtos com indicação de origem geográfica. A água, entretanto, escapa aos estudos clássicos sobre produtos com indicação de origem, possuindo particularidades no que se refere a sua inserção no mercado. As cadeias de comercialização são globais, e diferentemente da maior parte dos produtos que portam uma denominação de origem, é um mercado dominado por grandes grupos industriais, para quem a origem serve para segmentar uma oferta cada vez mais especializada.

O artigo se apresentará da seguinte forma: na seção 2 abordamos o contexto econômico e de mercado em que nosso estudo de caso se insere (a "transformação do recurso natural ao produto água envasada, o papel da montanha nesse processo, o mercado da água, especialmente na França e, por fim, as Marcas de Distribuidores (MDD) que vem utilizando o selo 'água de fonte de montanha' como forma de valorização da oferta); na seção 3 apresentamos o referencial teórico que utilizaremos na análise dos resultados de campo; na seção 4, será descrita a metodologia de coleta dos dados; a seção 5 será dedicada à apresentação e discussão dos resultados, enfim, tecemos algumas considerações finais.

\section{2 ÁGUA DE MONTANHA: DO RECURO NATURAL AO PRODUTO ÁGUA}

Em razão do declive, de solos pouco férteis, de temperaturas frias e pela dificuldade de acesso, as áreas montanhosas apresentam, em geral, taxas de ocupação baixas, pois os vales se prestam melhor à colonização, às atividades agrícolas e industriais. Essa realidade faz com que as fontes de água localizadas em zonas de altitude tenham menos contato com atividades potencialmente poluidoras ou contaminantes. Dessa forma, a água proveniente dessas fontes está relacionada à pureza ou a locais intocados pela mão do homem.

Na França, segundo a legislação, a água envasada pode ser classificada como: "água mineral natural" ou "água de fonte". Ainda, uma terceira categoria foi adicionada após a criação do selo "produto de montanha". O selo "água de fonte de montanha" pode ser utilizado por produtos cujas fontes se localizam a 600 metros de altitude ou mais.

O mercado de água no mundo é apontado como mais dinâmico segmento da indústria de bebidas, representa um volume anual de 89 milhões de litros e movimenta 22 milhões de dólares (WILK, 2006). A Europa Ocidental é o maior consumidor de água engarrafada, com uma média de consumo de 85 litros por pessoa por ano. Atualmente, os mercados mais atrativos e em expansão se encontram na Ásia e no Pacífico (FERRIER, 2001).
Como já referimos, trata-se de um mercado particularmente competitivo, dominado historicamente pelos grupos Nestlé e Danone. Algumas aquisições de usinas de envase foram realizadas pela Nestlé nos últimos anos, reforçando sua posição nesse mercado, onde a estratégia de desenvolvimento vem se dando através da compra de empresas que já atuam no mercado. Danone segue a mesma linha, apoiando-se em marcas e empresas também já conhecidas e presentes no segmento. $\mathrm{Na}$ China, conquistou dessa forma a liderança no mercado de água engarrafada, à frente de Coca-Cola e Nestlé, ela detém $48 \%$ do mercado. Coca- Cola, que vem procurando dissociar sua imagem de um produto que causa obesidade, vem investindo no segmento da água. Já fortemente presente nos Estados Unidos nesse domínio, tanto Coca-Cola, quanto Pepsi- Cola tem investido na Europa, onde Nestlé e Danone detêm as posições mais fortes, com concorrentes como o grupo francês Castels, ou o italiano San Benedetto. "O mercado da água em garrafa, como o da água em bombonas, se tornou um dos mercados mais disputados

do mundo"1 (DRANCOURT, 2005, p. 242). E entre as diferentes estratégias de marketing desse segmento, encontramos com frequência a referência à montanha.

\subsection{Estratégias de marketing e a montanha}

Com poucos elementos para diferenciar um produto como a água, as estratégias de marketing utilizam a imagem da marca e o segmento de mercado visado para se distinguir. Wilk (2006, p. 305) pontua com ironia o resultado: "hoje em dia os profissionais do marketing reconhecem que os bens possuem poderes mágicos que não têm nada a ver com as necessidades [...], a água é um exemplo excepcional e claro do poder da marca" ${ }^{2}$.

É verdade também que esse setor soube aproveitar muito bem as oportunidades de diversificação: é possível encontrar no mercado água aromatizada, que contém aspirina, cafeína, vitamina, e, mesmo, nicotina; ainda, água que ajuda a emagrecer, água boa para os animais de companhia, outras com origens bastante extravagantes, como água proveniente de geleiras ou icebergs (WILK, 2006).

As estratégias de marketing se apoiam com frequência na imagem da saúde, do bem-estar e da pureza. A pureza estando, na maioria dos casos, relacionada à qualidade da fonte, as embalagens mostram imagens que fazem uma referência direta à natureza - e mais precisamente à montanha. Olson (1999) estudou a publicidade, as embalagens e os sites na internet dos 50 membros da Associação Internacional de Água em Garrafa (IBWA) dos Estados Unidos, e os termos mais empregados na comunicação do produto foram:

\footnotetext{
1 «Le marché de l'eau en bouteille, comme celui de l'eau en bonbonnes, est devenu l'un des marchés les plus disputés du monde »

2 «Today marketers recognize that goods have magical powers that having nothing to do with needs [...], bottled water is an exceptionally clear example of the power of branding ».
} 
Quadro 1 - Termos utilizados na comunicação da água envasada nos EUA

\begin{tabular}{|l|c|}
\hline \multicolumn{1}{|c|}{ Termo } & Número de ocorrências \\
\hline Pura & 8 \\
\hline Natural/Prepada pela Natureza & 8 \\
\hline Água de Montanha $^{3}$ & 7 \\
\hline Primitivo $^{3}$ & 5 \\
\hline Premium & 5 \\
\hline Mais pura/Pureza & 3 \\
\hline $\begin{array}{l}\text { Purificada naturalmente/ Fonte } \\
\text { natural }\end{array}$ & 3 \\
\hline De geleiras & 2 \\
\hline Limpa & 2 \\
\hline Boa para a saúde/Saudável & 2 \\
\hline Para uma consciência sã & 2 \\
\hline Fonte: traduzido de Olson (1999) & \\
\hline
\end{tabular}

Na França, Bozonnet (1991, p. 109) analisou duas propagandas da marca Evian e o conteúdo simbólico empregado em relação à montanha. Na primeira, duas impressões se evidenciam: a "pureza", representada pela "brancura"; e a "dureza", representada por "ângulos retos", "arestas", "picos" e pela "frieza do azul". Segundo o autor, são elementos "estatisticamente encontrados na maioria das propagandas sobre montanha", pretendendo transmitir a ideia de pureza associada à fonte, e, por consequência, à água.

$\mathrm{Na}$ segunda propaganda, uma história em quadrinhos conta uma epopeia que inicia assim: "no começo, todas as águas eram puras". Em seguida, com a poluição que se generalizou, "apenas os Alpes conservaram a inocência original; hoje eles filtram e enriquecem a água que purifica nossos organismos". A imagem que fecha a história é a do interior de um corpo humano "feito de estratos geológicos purificadores". Essa propaganda se constitui "em pedagogia para demonstrar os mecanismos pelos quais as qualidades regeneradoras" da montanha são incorporadas e assimiladas pelo homem (BOZONNET, 1991, p. 109). De maneira geral, as marcas procuram associar seu produto a um conteúdo simbólico que se vale do mito da montanha purificadora, regeneradora - que se constituiu desde o fim da idade média, combinada com o mito da montanha 'higienista' (BALLION, 1981).

\subsection{O mercado da água envasada na França}

$\mathrm{O}$ mercado francês de água movimenta em torno de 8 bilhões de litros. O país é o terceiro consumidor da Europa. Trata-se de um mercado muito fechado e extremamente competitivo, dominado por três grandes grupos internacionais: Nestlé-Waters, Neptune-Castels e Danone-Eaux-France, os quais representam juntos mais de $60 \%$ do mercado em volume. Em faturamento os três agrupados superam $70 \%$ do mercado (AGRAALIMENTATION, 2008).

Na tabela 2, podemos ver que o consumo de água envasada na França quadruplicou desde 1970:
Quadro 2 - Consumo de água engarrafada na França

\begin{tabular}{|c|c|}
\hline Ano & $\begin{array}{c}\text { Consumo de água mineral ou de } \\
\text { fonte (litros) }\end{array}$ \\
\hline 1970 & 39,9 \\
\hline 1980 & 56,68 \\
\hline 1990 & 89,97 \\
\hline 2000 & 148,76 \\
\hline 2003 & 160,53 \\
\hline $2004 *$ & 144,48 \\
\hline $2007 * *$ & 135,14 \\
\hline $2009 * * *$ & 132,43 \\
\hline Fonte : INSEE, Comptes de la nation, base 2000. In : Régnier, \\
Lhuissier, Gojard (2006) \\
$*$ Fonte: Earth Policy Institut \\
$* *$ Fonte : ACNielsen \\
$* * *$ Fonte : Chambre syndicale des eaux minérales naturelles - \\
France
\end{tabular}

Entretanto, esse mercado vem apresentando um retraimento. Desde 2003, o consumo francês reduziu $10 \%$ em volume e valor. A redução constatada nos últimos anos se deve em parte à melhoria da imagem da água 'de torneira' por meio de campanhas publicitárias. De outra parte, há a imagem negativa associada à água envasada no que concerne ao meio-ambiente, especialmente em relação ao lixo gerado pelas embalagens e à pegada ecológica devida ao transporte do produto. Apesar de $100 \%$ das garrafas utilizadas no mercado francês serem recicláveis, apenas $50 \%$ são efetivamente recicladas (AGRAALIMENTATION, 2008).

As marcas que dominam o segmento na França são: Evian, Vittel, Contrex, Volvic, Hépar, que representam $56 \%$ do segmento em faturamento. A marca Cristalinne, cuja estratégia é vender pelo menor preço do mercado, tem a liderança em volume - sozinha ela responde por $21,9 \%$ das vendas. Em seguida temos as marcas de distribuidores (MDD) que representam, agrupadas, $21,2 \%$ das vendas em volume (RAYON BOISSON, 2012).

$\mathrm{O}$ posicionamento das águas MDD no mercado responde a uma dupla estratégia dos grupos varejistas (proprietários das MDD): (i) estabelecer concorrência com a gama 'primeiro preço' - a mais barata; e (ii) propor uma gama intermediária. Isso permite aos grupos uma segmentação a mais nas prateleiras, dado que esse produto se situa entre as marcas 'primeiro preço' e as grandes marcas de água de fonte ou água mineral (MOREAU; CLAPHMAN, 2006; MOREAU, 2007). As marcas que fazem parte dessa gama intermediária portam com frequência o selo "água de fonte de montanha", é o caso dos grupos E.E.Leclerc, Carrefour, Cora, Auchan e Casino.

\footnotetext{
${ }^{3}$ Tradução do termo em inglês "pristine", para o qual não encontramos equivalente perfeito em português.
} 


\subsection{As marcas de grandes distribuidores: do preço baixo às MDD com certificação}

Entre as MDD, temos diferentes gamas propostas pelos distribuidores, cada uma com objetivos distintos e complementares, o que tem a ver com a qualidade dos produtos. Eles podem visar à segmentação da demanda ou o ganho em poder de negociação com os grupos industriais, proprietários de marcas conhecidas.

Os primeiros produtos MDD franceses foram lançados pelo grupo Casino em 1901, essa iniciativa foi seguida pelos grupos Monoprix e Prisunic, em 1928 e 1931, respectivamente. Em 1976 o Carrefour lança Produits libres (Produtos Livres), uma gama em que o grupo decidia as características com objetivo de controlar os preços de finais e a margem de lucro (BERGÈS-SENNOU; CAPRICE, 2003). Esses produtos fazem parte do que chamamos hoje a primeira geração de MDD, cujas características são: ausência de referência explícita ao nome do grupo e simplicidade das embalagens. Isso fazia parte de uma lógica utilitária e funcional onde se buscava o essencial do produto, mais importante era a possibilidade de oferecer produtos de primeira necessidade a preços muito acessíveis. "A grande distribuição por muito tempo considerou que o principal desejo dos consumidores era a busca por produtos baratos ${ }^{4,}$. Essa primeira geração de MDD é, assim, muito próxima do que chamamos produtos 'primeiro preço' (MESSEGHEM, 2005, p. 62).

Depois dos MDD 'primeiro preço', os distribuidores começaram a trabalhar com uma oferta de segunda geração; é o que chamamos de MDD standards ou MDD me-too. Trata-se de produtos cujo efeito de substituição em relação às marcas de referência, chamadas marcas nacionais (MN), é forte. A qualidade entre os dois bens não difere de forma significativa, o que faz com que essa gama de MDD possa concorrer diretamente com as MN e, por consequência, permite aos distribuidores obter "concessões tarifárias por parte dos produtores de $\mathrm{MN}^{5 \text { " }}$ (BERGÈS-SENNOU et al.,

2006, p. 1).

Essa segunda geração de MDD tem como objetivo claro o ganho em poder de negociação pelos distribuidores em relação aos produtores de MN, enquanto a primeira geração obedecia a uma lógica de segmentação de mercado. Essa segmentação visava um público que se interessava em comprar produtos com preços bastante atraentes, mas de qualidade inferior às MN.

A terceira geração de MDD visa também uma segmentação da oferta. Entretanto, essa nova geração obedece à outra lógica. Os novos MDD apoiam-se em "cadeias de produtos que se posicionam em qualidade

\footnotetext{
${ }^{4}$ « La grande distribution a longtemps considéré que la principale attente des consommateurs était la recherche des produits bon marché »

5 «des concessions tarifaires de la part des producteurs de $\mathrm{MN} »$
}

mais elevada e a preços superiores em relação à oferta média ${ }^{6}$ " (FONTGUYON et al., 2003, p. 86).

Antes os MDD tinham como alvo uma demanda funcional, todavia, assim que esse valor de uso se encontrou satisfeito, a demanda incorporou uma parte crescente de valor imaterial (MOATI, 2005; MAGALI, 2009). Buscando suprir esse nicho é que surgem as gamas de MDD terceira geração, onde os MDD de terroir se encontram. O Quadro 3 apresenta algumas das mais conhecidas gamas de MDD do mercado francês, podemos identificar os MDD de primeira ('primeiro preço') e de segunda (Grupo/Standards) geração, mas igualmente gamas que compõem a terceira geração.

Quadro 3 - Diferentes gamas de MDD encontradas no mercado francês

\begin{tabular}{|c|c|c|c|c|}
\hline $\begin{array}{l}\text { Tipos } \\
\text { MDD/Grupos }\end{array}$ & Auchan & $\begin{array}{c}\text { Carrefou } \\
\mathbf{r} \\
\end{array}$ & Casino & $\begin{array}{c}\text { E. } \\
\text { Leclerc }\end{array}$ \\
\hline $\begin{array}{l}\text { MDD Primeiro } \\
\text { preço }\end{array}$ & Pouce & $\begin{array}{l}\text { Carrefour } \\
\text { Discount }\end{array}$ & $\begin{array}{c}\text { Euro } \\
\text { Sourire }\end{array}$ & $\begin{array}{l}\text { Eco } \\
\text { Plus }\end{array}$ \\
\hline $\begin{array}{l}\text { MDD } \\
\text { Grupo/Standards }\end{array}$ & Auchan & Carrefour & Casino & $\begin{array}{l}\text { Marque } \\
\text { Repère }\end{array}$ \\
\hline MDD Bio & $\begin{array}{c}\text { Auchan } \\
\text { Bio } \\
\end{array}$ & $\begin{array}{c}\text { Carrefour } \\
\text { Agir } \\
\end{array}$ & $\begin{array}{c}\text { Casino } \\
\text { Bio } \\
\end{array}$ & $\begin{array}{c}\text { Bio } \\
\text { Village }\end{array}$ \\
\hline MDD Premium & Mmmm... & $\begin{array}{l}\text { Carrefour } \\
\text { Sélection }\end{array}$ & $\begin{array}{l}\text { Casino } \\
\text { Délices }\end{array}$ & - \\
\hline MDD Temática & $\begin{array}{c}\text { Invitation } \\
\text { s au } \\
\text { voyage }\end{array}$ & $\begin{array}{l}\text { Reflets de } \\
\text { France }\end{array}$ & $\begin{array}{c}\text { Casino } \\
\text { Saveur } \\
\text { d'ailleur } \\
\text { s }\end{array}$ & $\begin{array}{c}\text { Nos } \\
\text { Région } \\
\text { s ont du } \\
\text { Talent }\end{array}$ \\
\hline
\end{tabular}

Fonte: Lapoule, Menvielle (2008)

A gama de MDD terceira geração comporta diversas segmentações, entretanto a categoria que responde pelo maior faturamento dentre elas é a de produtos de terroir, como podemos verificar no Quadro 4.

Quadro 4 - Divisão do faturamento dos MDD temáticos na França

\begin{tabular}{|l|c|}
\hline Segmentação & $\begin{array}{c}\text { Faturamento em relação a gama } \\
\text { MDD temática em \% }\end{array}$ \\
\hline Terroir & $45,60 \%$ \\
\hline Premium & $9,30 \%$ \\
\hline Saúde e Biológico & $21,40 \%$ \\
\hline Infantil & $11,60 \%$ \\
\hline Exóticos & $11,80 \%$ \\
\hline
\end{tabular}

Fonte: Lapoule, Menvielle (2008)

No que se refere ao consumo, parece haver um efeito positivo na combinação entre um selo de Denominação de Origem ou Indicação Geográfica e a oferta MDD. Hassan e Monier-Dilhan (2004) demonstraram que produtos MDD combinados a selos de indicação de origem atingiram valores de venda maiores do que produtos de grandes marcas (o que referimos já como MN) combinados com esse mesmo selo. Essa estratégia permite aos grupos varejistas

\footnotetext{
${ }^{6}$ « filières de produits qui se positionnent en qualité plus élevée et à des prix supérieurs à ceux de l'offre moyenne de produits non différenciés »
} 
melhorar a qualidade percebida e sua imagem perante o consumidor.

Como já havíamos mencionado, no mercado francês as marcas de água que portam com maior frequência o selo 'produto de montanha', como forma de agregar valor ao produto, são as MDD. No que diz respeito à relação entre distribuidores e produtores, ou fornecedores, os MDD fortemente diferenciados tendem a funcionar segundo uma lógica de cadeia (FONTGUYON et al., 2003; CODRON et al., 2005), quer dizer, as relações estabelecidas ao longo da cadeia de produção seriam mais de tipo cooperativo. Os MDD "Premium" implicariam assim em uma forte colaboração entre fabricantes e distribuidores, e numa certa estabilidade de relações: "o desenvolvimento dos produtos e as inovações são esforço conjunto, onde a interação é maior" (COLLA, 2007, p. 10).

Para outros, entretanto, o fortalecimento e a sofisticação dos esquemas MDD estão inseridos num contexto de redefinição do papel da grande distribuição, onde vemos um aumento da importância de suas funções comerciais. Os grupos agora passariam a exercer também um papel de ajustamento qualitativo entre oferta e demanda. A grande distribuição tenderia a se tornar um agente ativo na cadeia de produção, além da transmissão de informações a montante e a jusante, ela interviria na definição mesmo das características dos produtos, sejam essas físicas ou simbólicas (MOATI, 2005).

Nesse contexto, nos perguntamos sobre a maneira através da qual se faz o fornecimento de água de montanha aos grandes grupos de distribuição. De que tipo de usina seria proveniente o produto e quais seriam as relações entre distribuidores e usinas.

\section{REFERENCIAL TEÓRICO}

Nosso objetivo é analisar a influência da relação empresa-território, no caso das usinas que 'produzem' água envasada em zonas de montanha. As zonas de montanha são tidas como zonas desfavorecidas, cujo difícil acesso, fraca densidade demográfica e econômica se constituem normalmente entraves para o desenvolvimento de negócios. Por outro lado, propomos um estudo onde o objeto é um produto que tem forte relação e identificação com esse território, sua origem podendo se constituir em estratégia de valorização da oferta. Dessa forma buscamos um referencial para analisar não apenas a influência da localização no funcionamento e nas escolhas das empresas, mas também para verificar se tal localização pode fornecer uma vantagem em termos de argumento de valorização e como ela é utilizada.

\subsection{Território: oportunidade de negócios e diferenciação}

A priori, a variedade de objetos que se depreendem da atividade de empreender seria um dos entraves para que

\footnotetext{
${ }^{7}$ « Le développement des produits et les innovations sont un travail conjoint, comportant davantage d'interaction »
}

a atividade empresarial se constituísse em projeto de pesquisa (VERSTRAETE, 2002). Em contraposição, há certo acordo sobre a existência de quatro grandes paradigmas de análise (VERSTRAETE; FAYOLLE, 2005): o paradigma da oportunidade de negócios, o paradigma da criação de valor, o paradigma da criação de uma organização e o paradigma da inovação.

O paradigma da oportunidade de negócios se inspira dos trabalhos da escola austríaca, e em particular de dois autores: Schumpeter et Kizner. No entanto, existe um debate sobre o caráter objetivo ou subjetivo das oportunidades, onde "é possível opor duas concepções ontológicas relativas às oportunidades: a descoberta e o enactment (ativação/colocação em prática) ${ }^{8,}$ (MESSEGHEM, 2006, p. 5).

Uma primeira orientação vê na oportunidade uma realidade objetiva que pode ser identificada através da análise de certos dados e informações. Esse approache, de inspiração positivista sugere que a oportunidade existe independentemente dos empreendedores, a eles de utilizar as ferramentas e as capacidades de interpretação para colocá-las em funcionamento e transformá-las em realidades econômicas (SHANE; VANKATARAMAN, 2000). Tal orientação se interessa particularmente em pesquisar os processos cognitivos utilizados pelos indivíduos na identificação de oportunidades (KAISCH; GILAD, 1991; ZAHRA et al., 2005).

A segunda corrente segue uma perspectiva construtivista, "onde a oportunidade é uma construção social que nasce de interações e confrontações entre os proponentes do projeto de empreender e seu contexto de evolução" (VERSTRAETE; FAYOLLE, 2005, p. 35). Se a oportunidade pode ser considerada como "uma situação futura julgada desejável e factível ${ }^{10}$,, nesse caso, ela pode também ser construída (STEVENSON; JARILLO, 1990, p. 23).

Esse approache se vale do "ponto de vista do mercado, mas sem excluir a intervenção ou a capacidade empreender, e o ambiente (um território, uma rede, um mercado...) enquanto portador de informações a serem coletadas, analisadas e interpretadas ${ }^{11 "}$ (VERSTRAETE; FAYOLLE, 2005, p. $35)$.

Segundo Verstraete e Fayolle (2005, p. 44) "uma oportunidade é explorada apenas se ela é percebida como suscetível de gerar valor, ao menos para aquele que a identificou (podendo a identificação remeter à detecção, à construção ou à combinação entre

\footnotetext{
8 «il est possible d'opposer deux conceptions ontologiques relatives aux opportunités : la découverte et l'enactement (mise en scène, activation) »

9 « où l'opportunité est une construction sociale naissant des interactions et des confrontations entre les porteurs du projet d'entreprendre et leur contexte d'évolution »

10 « une situation future jugée désirable et faisable »

11 «point de vue du marché, sans exclure l'intervention ou les facultés de l'entrepreneur, l'environnement (un territoire, un réseau, un marché, ...) comme porteur d'informations à collecter, à analyser et à interpréter »
} 
ambos) $)^{12 \%}$. Nesse sentido, a diferenciação de produtos alimentares, particularmente através da origem, poderia se constituir em uma oportunidade para as empresas alimentares situadas em zonas de montanha. Essa oportunidade poderia trazer benefícios não apenas para as empresas, mas também para seu território de implantação, qual seja a montanha.

A promoção da origem no setor agroalimentar tornou-se nos últimos vinte anos um fator importante de reconhecimento junto a consumidores e um suporte de notoriedade para os produtores (VALSESCHINI, 2000). Muitos produtos com estreita relação com seu território de origem portam o que se chama em francês de efeito terroir: interação entre ambiente natural e atividades humanas. Trata-se de produtos cujas características são influenciadas pela dimensão cultural (modos de cultivo, modos de preparo e de processamento dos alimentos, receitas) e pela dimensão física-ambiental (características edafoclimáticas, variedades vegetais adaptadas, raças animais adaptadas) do território (BARJOLLE; BOISSEAUX; DUFOUR, 1998). Pretendemos verificar como as estratégias de diferenciação empregadas por cada uma das empresas relacionam e evidenciam as dimensões territoriais da montanha, pois seus processos estratégicos podem agregar valor ao produto (LORINO; TARENDEAU, 2006).

Além do setor, a estrutura da empresa também influencia a escolha de suas estratégias, bem como seu posicionamento no mercado, poder de investimento, negociação. Esses elementos se refletirão no modo como essas unidades se relacionam com seu setor de atividades e com seu sítio de implantação, considerando uma empresa composta por um único estabelecimento, ou uma empresa pertencente a uma organização maior. Nesse caso, as relações da unidade com o grupo devem ser analisadas.

Para dar conta dessas inter-relações, nós adotamos a proposição de Colletis et al. (1997), onde a unidade industrial (filial ou estabelecimento) localizada será o ponto de mediação. Ou seja, a unidade articula as relações locais, do setor e de seu grupo. A força ou a superposição de uma relação sobre outra permite a ancoragem da empresa em relação ao território. Essa tripla modalidade de inserção é representada pelo esquema da figura seguinte:

12 «Une opportunité n'est exploitée que si elle est perçue comme susceptible de dégager de la valeur au moins pour celui qui l'a identifiée (l'identification peut renvoyer à la détection, à la construction ou à la combinaison des deux) »

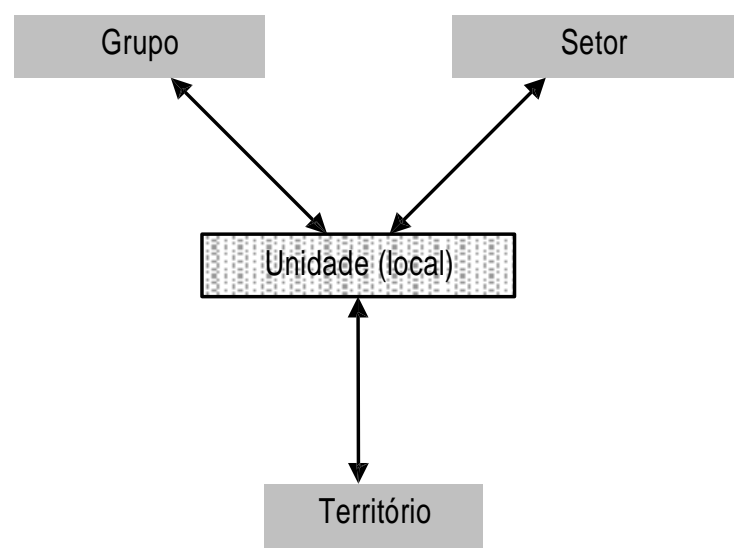

Figura 1 - Quadro relacional da empresa

Fonte: adaptado de Colletis et al., 1997.

\section{METODOLOGIA}

Nosso artigo é um estudo de caso sobre um produto que é frequentemente associado aos territórios de montanha e que ainda é pouco estudado. Para responder a nossas questões de pesquisa, entrevistamos os responsáveis de duas empresas que extraem água de fontes situadas em montanha. Cada uma dessas empresas apresenta uma estrutura diferente, e tais diferenças influenciam, como veremos, suas estratégias de comercialização e comunicação.

Foram ouvidos os responsáveis das empresas Aquamark e Société d'Exploitation des Eaux de Montagne (SEEM). Aquamark é uma usina que pertence a um grande grupo de distribuição francês, o grupo E.Leclerc. SEEM é uma $\mathrm{PME}^{13}$ independente.

Nós também entramos em contato com outras empresas $^{14}$, explicando os objetivos de nossa pesquisa, entretanto, não obtivemos resposta dos responsáveis das marcas Volvic, Mont-Dore et Arcens. Os responsáveis pela Eau Minérale de Vals e pela Rosée de la Reine responderam negativamente a nossa demanda, justificando que seus produtos não se enquadrariam em nosso estudo. Como vimos anteriormente, trata-se de um mercado muito fechado, onde a concorrência é muito acirrada. Tais fatores podem explicar a reticência por parte das empresas em falar sobre suas estratégias comerciais.

As duas empresas que aceitaram responder às nossas questões se localizam em zonas de montanha, SEEM na cidade de Le Perrier, Aquamark, em Laqueuille - cidade que empresta seu nome ao produto da usina.

\footnotetext{
13 Pequenase médias empresas

${ }^{14}$ Eau minérale de Vals (Société des eaux minérales de Vals, Ardèche ; groupe Alma); Arcens («Eau minérale naturelle gazeuse des montagnes de l'Ardèche »; Société Anonyme d'exploitation des sources, Ardèche ; groupe Alma) ; Rosée de la Reine (Société des eaux de Mont Roucous, Tarn ; groupe Danone) ; Mont-Dore (Société des eaux du Mont Dore, Auvergne ; groupe Alma) ; Volvic (Auvergne, groupe Danone).
} 


\section{RESULTADOS E DISCUSSÃO}

\subsection{Duas inserções territoriais distintas}

A cadeia de produção é relativamente simples, do ponto de vista dos agentes envolvidos. Com efeito, ele não demanda mais que um agente desde a obtenção da matéria prima a obtenção do produto final: a empresa que explora a fonte e envasa o produto - sendo o processo caracterizado pelo emprego de equipamentos de alto nível tecnológico. À jusante, temos as empresas que fornecem os recipientes para envase, tampas, etiquetas, equipamentos, assistência, manutenção. distintas

Em relação à distribuição temos duas situações

A água Laqueuille passa somente pelo distribuidor do grupo E.Leclerc, organizado sob a forma de uma central de compras nacional e 16 centrais de compras regionais, antes de chegar às 510 lojas E.Leclerc distribuídas em toda França e outras situadas em demais países europeus. Mais de $50 \%$ desses pontos comerciais se encontram fora de zonas de montanha.

A água Valécrin, produzida pela SEEM, utiliza diferentes vias para acessar os diferentes mercados. A SEEM trabalha com distribuidores diferentes e empresas subcontratadas que fazem o transporte da mercadoria até os clientes finais, constituídos em grande parte por pontos comerciais ou restaurantes situados na região dos Alpes. Em menor escala, o produto chega a pontos comerciais na Ásia, já que a água Valécrin é exportada em pequena quantidade, segundo nosso entrevistado, para China e Japão.

Sobre os arranjos ao longo da cadeia de distribuição, a SEEM procede por meio de contratos formalizados quanto a volume e preço. Em geral são contratos de curta duração, menos de um ano. Para Aquamark, a cadeia de distribuição é integrada, sua organização é centralizada e a coordenação fica a cargo do grupo E.Leclerc.

Segundo nossos entrevistados, os laços entre os agentes da cadeia não apresentam um caráter de relações pessoais, como pode ser o caso em muitos produtos com forte relação com seu território de origem. Para Vázquez-Barquero (2002), as relações pessoais podem proporcionar trocas de informações, de recursos necessários à formação e à colocação em prática de um projeto, favorecendo também a troca de bens, de serviços e de saber-fazer. Entretanto, a rede de empresas é baseada em trocas em nível de negócios, de serviços de apoio técnico, de recursos financeiros e materiais. Esses movimentos de troca que prescindem de contatos pessoais permitem a formação de ligações estratégicas que tem como objetivo melhorar os resultados de todos os participantes, é o caso da SEEM.

A empresa conta com o apoio das coletividades locais e da Agência de Desenvolvimento Local Matheysine. Matheysine construiu as instalações onde funciona a SEEM, as quais são sublocadas em forma de leasing. O investimento de 1,36 milhões de euros deverá ser pago em 15 anos, o responsável da Agência destaca, entretanto, que, mais importante que o retorno do investimento, é o interesse em promover o emprego local. Recentemente, a SEEM estabeleceu uma parceria com o Departamento de Turismo da região RhôneAlpes para que Valécrin se torne a água referência "Puro Bem Estar", isso permite melhorar a visibilidade do produto, o que poderá representar um aumento de vendas localmente.

Diferentemente das redes pessoais, as atividades têm um papel central nas redes de empresas, pois elas são o ponto de partida de relações de interdependência, no sentido em que os resultados de cada atividade exercem influência sobre os resultados do todo (VÁZQUEZBARQUERO, 2002). Assim, o interesse das coletividades locais, Agências de Desenvolvimento e Turismo é o de estimular a atividade econômica da região e, portanto, tais instituições apoiam as atividades da SEEM. Essa última responde em termos de criação de empregos e de riqueza localmente, é um círculo virtuoso para o território que favorece a proximidade institucional.

Analisemos especificamente a influência do setor de atividade, qual seja, o de água envasada, sobre as duas empresas.

As duas empresas afirmam não passar por dificuldades maiores com relação a sua produção. No entanto, a questão da comercialização para a SEEM não deixa de ser um problema, pois precisa competir com grupos e empresas que operam em escalas muito maiores, e ainda com os MDD - o que significa dizer com o próprio varejo. Assim, a empresa multiplica contatos em busca de apoio de diferentes parceiros. Ela conta assinar um contrato com um grande grupo de distribuição francês para colocar no mercado uma marca de água MDD. Esse contrato estava ainda em discussão no momento em que fizemos esse estudo. Caso se concretize, permitiria à empresa ter acesso às prateleiras das lojas desse distribuidor por duas vias: não apenas como fornecedor do produto MDD, mas também pela possibilidade de colocar a água Valécrin em um grupo de alcance nacional.

As relações dessa unidade com seu setor de atividade e com seu território poderiam ser representadas da seguinte forma:

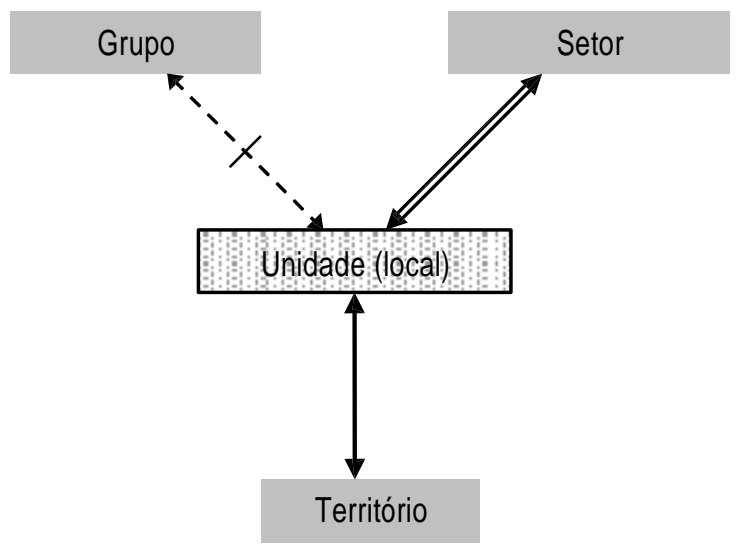

Figura 2 - Quadro relacional da empresa SEEM (Valécrin) 
Em contraste, Aquamark serve a uma estratégia de diversificação: a criação de uma gama de produtos para as lojas do grupo E.Leclerc.

A produção da empresa permite ao grupo uma dupla segmentação no mercado com um único produto. É preciso esclarecer que Aquamark fornece a água 'primeiro preço' E.Leclerc: Eco+, que tem origem na mesma fonte que a Laqueuille. A diferença é a embalagem utilizada, para Eco+ mais simples, bem como sua etiquetagem. Ou seja, temos uma usina de onde saem dois produtos iguais, mas distintos: a água Eco+ e a água Laqueuille, essa última, parte da marca guarda-chuva Repère (que abordaremos na seção seguinte). $\mathrm{O}$ grupo atinge assim uma clientela que busca produtos funcionais a preços baratos com a água Eco+. $\mathrm{E}$, ao mesmo tempo, oferece uma gama do que chamamos nova geração de MDD, que se posiciona no segmento de qualidade e preços mais elevados.

A estratégia MDD de terroir, que utiliza o termo "água de fonte de montanha", nesse caso, não é um arranjo cooperativo entre um grande grupo e uma PME, como se verifica em outros exemplos (BRETON, 2004; MESSEGHEM, 2004, 2005; LAPOULE, 2007). O produto tem origem em empresa pertencente ao grupo e serve ao objetivo de oferecer uma gama suplementar nas prateleiras dos supermercados, permitindo trabalhar melhor suas margens de lucro.

Em termos de atividade empreendedora, a situação da unidade não pode ser classificada como criação de uma empresa ex-nihilo, devido ao fato de pertencer ao grupo E.Leclerc. Trata-se de uma empresa nova, mas que não é independente, cujas necessidades financeiras, de recursos outros, bem como de mercado são asseguradas pelo grupo do qual ela faz parte. O que temos é a criação de uma nova atividade dentro de uma organização já existente. A empresa Aquamark não pode ser analisada de forma independente do grupo E.Leclerc, essa uma grande empresa cuja lógica de funcionamento é se desenvolver, crescendo e estendendo suas atividades para além da distribuição.

A construção da oportunidade de negócios obedece aqui à lógica estratégica do grupo, as relações entre Aquamark e E.Leclerc são hierárquicas e de dependência. Aquamark, nesse contexto, representa uma segurança em termos de fornecimento, mas também a possibilidade de melhorar os resultados econômicos das lojas através das margens de lucro obtidas nesses produtos, e ainda, de participar de um setor dominado por grupos de envergadura mundial.

Assim, na tripla modalidade de inserção proposta por Colletis et al. (1997), temos um predomínio dos interesses do grupo. O laço com o território não é tão pronunciado como no caso da SEEM, e a relação entre grupo e setor, nesse caso, será mais pautada pela agenda da grande distribuição do que do setor de bebidas propriamente. $\mathrm{O}$ grupo busca propor uma gama de bens e serviços diversificados para fidelizar sua clientela. $\mathrm{O}$ argumento que federa essa oferta é o do poder de compra. Ou seja, o grupo evoca um mesmo argumento, um mesmo discurso de comunicação, com o objetivo de que os consumidores associem a(s) marca(s) E.Leclerc à qualidade a preços mais acessíveis do que a concorrência.

A representação dessa articulação seria a seguinte:

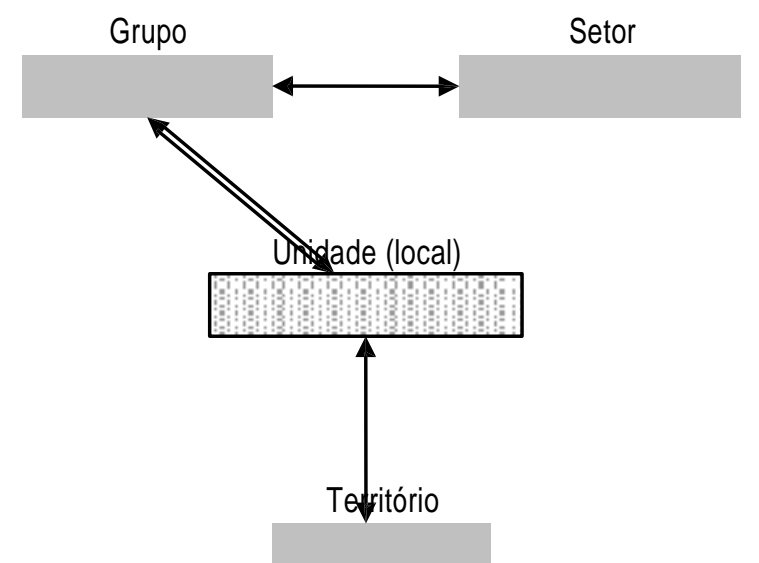

Figura 3 - Quadro relacional da empresa Aquamark (Laqueuille et Eco+)

No que se refere a benefícios para o território de implantação das empresas, solicitamos aos entrevistados que apontassem, em nível econômico, social e ambiental o que suas empresas ou atividades trariam de benefícios para a montanha. Segundo dados da Câmara Sindical das Águas de Fonte (Chambre Syndicale des Eaux de Source), a contribuição mais importante das sociedades de exploração de água de fonte para o desenvolvimento local é via incremento orçamentário dos municípios onde essas fontes estão localizadas e a criação de postos de trabalho. Os municípios recebem das empresas implantadas em seu território uma taxa profissional. Eles podem recolher também um imposto estipulado através de contrato entre as partes. $\mathrm{Na}$ França, o número de empregos diretos gerados pela indústria de água envasada é estimado em 10.000 postos de trabalho. O número de empregos indiretos, sem considerar a atividade termal, é estimado em mais de 30.000 .

As respostas dos diretores de Aquamark e SEEM seguiram exatamente essa mesma linha de argumentação, eles enfatizaram o pagamento de royalties aos pequenos municípios onde estão localizadas as usinas e a criação de postos de trabalho ver Quadro 5.

\subsection{A origem montanha na estratégia de diferenciação}

Os produtos estudados são vendidos como produtos de montanha, mas a referência não é utilizada da mesma forma. A água Valécrin é vendida como "água de fonte dos Alpes". O fato da fonte estar localizada no Parque Nacional dos Ecrins é mais importante que a origem 'montanha', pois isso permite vender um "produto dos Alpes", referência geográfica mais precisa e mais valorizada pelos consumidores, segundo o responsável da SEEM. 
$\mathrm{O}$ produto possui uma embalagem azul que remete à imagem da montanha nevada de alta altitude. O nome "Valécrin", segundo o entrevistado, auxilia os consumidores a associar a água à região alpina. $\mathrm{O}$ selo
Os dois entrevistados julgam que seus produtos apresentam qualidade superior devido ao fato de que 'suas' fontes se localizarem em zonas de montanha. Para o responsável da Aquamark, as características mais

Quadro 5 - Quadro síntese das empresas estudadas

\begin{tabular}{|c|l|l|}
\hline Temas & \multicolumn{1}{|c|}{ SEEM } & \multicolumn{1}{c|}{ Aquamark } \\
\hline Empregos & 9 empregados & 25 empregados \\
\hline Mercado & Nacional - França & Nacional - França \\
\hline Faturamento & 3,6 milhões Euros/ano & 20 milhões Euros/ano \\
\hline Oportunidade de negócios & Empresa + instituições locais & Empresa + Grupo E.Leclerc \\
\hline Ancrage Territorial & $\begin{array}{l}\text { Matéria prima }+ \\
\text { rede de empresas/instituições }\end{array}$ & Matéria prima \\
\hline Benefícios para a montanha & $\begin{array}{l}\text { Criação de empregos + orçamento } \\
\text { municipal }\end{array}$ & $\begin{array}{l}\text { Criação de empregos + orçamento } \\
\text { municipal }\end{array}$ \\
\hline $\begin{array}{c}\text { Dificuldades ligadas à } \\
\text { localização }\end{array}$ & Custo de transporte & Custo de transporte \\
\hline Elemento de diferenciação & Alpes & Montanha \\
\hline
\end{tabular}

"produto de montanha" não é utilizado desde 2005.

Entre os anos 2000 e 2001, a etiqueta da Valécrin portava também o selo oficial do Parque Nacional "Les Ecrins", entretanto, seu uso foi abandonado em 2002 devido ao custo, considerado alto: 0,015 €/garrafa.

Para Aquamark, empresa que produz a água Laqueuille, a origem é destacada sobretudo através da etiqueta. A água Laqueuille é comercializada na gama "Repère", uma marca guarda-chuva do grupo E.Leclerc que sinaliza aos clientes "produtos de qualidade superior por preços de 25 a $30 \%$ mais baratos". Ainda que a localização da fonte seja indicada no rótulo - com informações precisas sobre sua altitude, e que o desenho faça referência aos picos vulcânicos do Massif Central francês, o produto aposta na montanha 'genérica'. A embalagem porta o selo "produto de montanha" de maneira visível, e sua descrição é "Água de fonte de montanha".

\section{Figura 4 - Detalhe da embalagem das marcas de} água Valécrin e Laqueuille

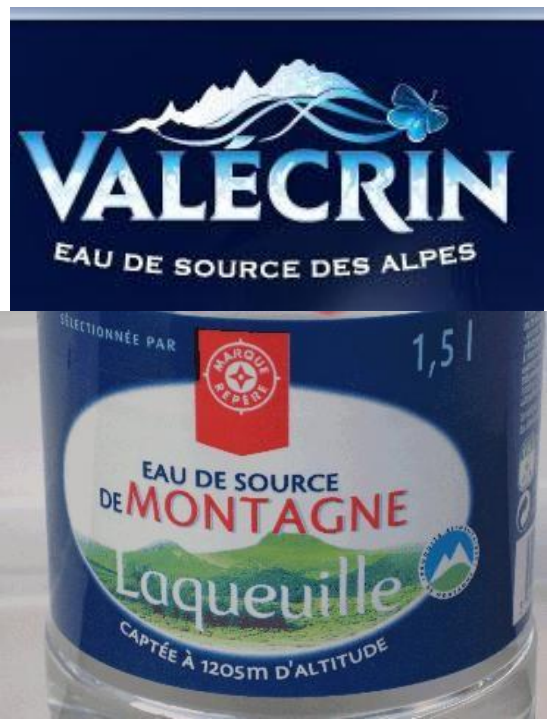

marcantes do produto são: o "gosto" e a "pureza".

Para o proprietário e dirigente da SEEM, são o "ambiente natural da produção" (poderíamos interpretar como o 'ambiente natural da fonte'), a "pureza", a "autenticidade do produto", e a "qualidade da matéria prima". Para os entrevistados, as características mencionadas são totalmente ligadas à origem "montanha".

Localmente, a SEEM trabalha sua notoriedade patrocinando clubes e eventos regionais. $\mathrm{O}$ diretor da empresa está convencido do potencial de imagem da região dos Alpes para imprimir a seu produto uma ideia de autenticidade. No que diz respeito à água Laqueuille, as características positivas do produto, segundo o responsável da usina, "são comunicadas pela descrição/nome do produto 'Água de fonte de montanha"".

No que se refere à relação entre origem e qualidade do produto, vemos que os entrevistados estão de acordo sobre o fato de que seu produto é diferenciado e que tal diferenciação é comunicada convenientemente aos consumidores. Resta investigar se isso se traduz em uma valorização do produto do ponto de vista econômico.

No caso de Aquamark, pudemos constatar que a referência à montanha constitui uma via de valorização que permite ao grupo E.Leclerc a oferta de uma gama intermediária em suas prateleiras situada entre os produtos de marca nacional e a gama 'primeiro preço'. Em média, a garrafa de 1,5 litros da água Laqueuille é vendida a $0,18 € /$ litro, enquanto a Eco+ (marca de água 'primeiro preço' do grupo) é vendida por 0,10 €/litro. Para SEEM, a origem também permite uma valorização, em média, para as garrafas de 1,5 litros, a água Valécrin é vendida a $0,22 € /$ litro.

Podemos concluir que a origem "montanha", seja ela genérica, ou mais específica - no caso da referência direta aos Alpes, se constitui em estratégia para a diferenciação (PORTER, 1999) do produto água 
envasada no mercado. No caso da água de fonte de montanha, estamos diante de um processo de produção, ou seja, de extração e engarrafamento, que mobiliza tecnologia de ponta. De fato, nossos entrevistados destacaram o investimento em maquinário que lhes permite ter um processo totalmente automatizado. Assim, quando examinamos os meios pelos quais as usinas de água buscam diferenciar sua oferta, percebemos que noções como saber-fazer e métier não podem ser utilizadas da mesma forma como os demais produtos alimentares que investem na origem como fator de singularização. Trata-se de uma expertise industrial, que permite buscar água em alta altitude, onde a 'natureza é intacta, preservada do contato com as atividades humanas'. E exatamente isso que faz com a água de montanha seja percebida um produto de 'melhor qualidade'.

A literatura sobre valorização da origem, por selos ou certificações, considera a dimensão física e geográfica do território, mas se legitima especialmente através da dimensão cultural - pela noção de métier e saberes desenvolvidos e compartilhados ao longo do tempo (BARJOLLE; BOISSEAUX; DUFOUR, 1998; FORT; FORT, 2006). Esse referencial se mostra, assim, limitado para analisar a água enquanto alimento e mercadoria, devido a sua especificidade. Pois, se a natureza, quando relacionada à sua origem, poderia reaproximar consumidores de produtores, depois de uma 'separação' devido a processos industriais standardizados, encontramos, no caso da água, uma natureza deserta de homens.

Como Wilk (2006), Bozonnet (1991) e Opel (1999) demonstraram, todo o esquema de comunicação de águas engarrafadas visa legitimar a pureza do produto. Em comparação com produtos onde se busca destacar a singularidade de um saber-fazer, a comunicação em torno da água é oposta. Ela apresenta o produto em si, tornando os agentes que se ocupam de sua produção 'invisíveis'. A insistência, através de imagens onde apenas a natureza selvagem aparece, tem como efeito 'apagar' todos os processos de captação, envasamento e transporte por que passam o produto. Nesse sentido, a água nunca é personalizada, o que deve ficar para os consumidores é a ligação do produto com sua fonte de origem.

Esse esquema ajuda de certa forma a dissimular os impactos ambientais por trás dessa indústria. Para cada garrafa de água mineral produzida são geradas 100 gramas de emissões de $\mathrm{CO} 2$. Um dos principais problemas é a embalagem de politereftalato de etileno, ou PET, e o transporte do produto. Apenas nos Estados Unidos a quantidade anual de petróleo utilizada para fabricação de embalagens PET poderia abastecer um milhão de automóveis. No Brasil o transporte da água é feito essencialmente através do modal rodoviário.

Outro grande problema é a destinação dessa embalagem. Mesmo no caso de descarte correto, há impactos causados pela emissão de $\mathrm{CO} 2$ na coleta e transporte do lixo. Considerando uma taxa de reciclagem de $50 \%$ do consumo, uma garrafa PET gera aproximadamente oito vezes o seu próprio peso em resíduos, levando em conta as emissões atmosféricas, efluentes líquidos e resíduos sólidos. No caso de não serem destinadas corretamente, o problema é ainda maior, pois as embalagens acabam parando em rios e nos oceanos e demoram milhares de anos para serem absorvidas (VALT, 2004).

A cadeia da água também não quantifica, nem repassa o custo de seu impacto ecológico, ou seja, as externalidades negativas são socializadas. "O valor de mercado para água engarrafada é contabilizado no preço, [entretanto] os danos causados ao meio ambiente não são totalmente apreciado no custo final. Dessa forma, são desconsideradas as implicações ecológicas da cadeia produtiva da água mineral [sic]." (SILVEIRA; ROQUETE; OLIVEIRA, 2013, p. 16).

\section{CONSIDERAÇÕES FINAIS}

As principais contribuições do nosso estudo foram: (i) a utilização de recorte espacial ainda pouco utilizado para análise da produção alimentar: o território 'montanha', (ii) o produto escolhido: a água engarrafada, por tratarse de um recurso natural importante nessas áreas e que escapa aos estudos clássicos sobre produtos com indicação de origem.

Os produtos alimentares de montanha podem constituir uma oportunidade de negócios no contexto de valorização de produtos locais de uma maneira geral. A oportunidade seria não apenas uma realidade concreta, mas o resultado de uma construção social. Por parte da demanda, o contexto está ligado a questões de sociedade, de mudanças nos modos de vida, de revalorização de amenidades e especificidades locais.

A montanha nesse contexto é mobilizada nos processos de construção das oportunidades de negócios localmente, mas no caso estudado as usinas estão submetidas mais a questões setoriais do que territoriais. Essa construção, para uma das empresas perpassa, além disso, uma rede de apoio territorial de fato. Mas para a empresa pertencente ao grupo de distribuição, o negócio 'água envasada' conta com suporte e cumpre um objetivo definido dentro de uma estratégia maior, ligada ao varejo.

Em comum, a exploração de um recurso natural essencialmente identificado com territórios de montanha: a água. Essa relação, como vimos, é destacada no modo de apresentação do produto e permite valorizá-lo. Entretanto, a montanha evocada nos rótulos de água interpela os consumidores de maneira romântica, pois transmitem uma ideia de que a pureza provém da natureza intocada, inacessível, protegida.

Destacamos que outras relações com o segmento 'água em garrafa' e o território montanha poderiam emergir se pudéssemos ter analisado outras empresas. Isso não foi possível dada dificuldade em encontrar empresas dispostas a participar da pesquisa.

Sobre sua contribuição para a montanha, é preciso considerar que a criação de empresas possibilita a criação de riqueza e de emprego. Com exceção das cidades onde as estações de esporte de inverno são 
responsáveis pela atração de investimentos, as zonas de montanha permanecem, por sua baixa densidade demográfica, de serviços e de infraestrutura, menos interessantes para o estabelecimento de novos negócios. Por outro lado, precisamos ponderar que a água em garrafa é um produto bastante discutível em termos de sustentabilidade em longo prazo, cujo processo de extração e envase é tecnificado e pouco demandador de mão-de-obra, cuja pegada ecológica inclui transportar pequenas garrafas de água a grandes distâncias.

\section{AGRADECIMENTO}

O presente estudo foi financiado pela Comissão Européia - DG Recherche, através do Projeto de Pesquisa EuroMARC (European Mountain Agrofood Products, Retailing and Consumers).

Aos pareceristas anônimos da Revista Eletrônica Científica da UERGS pelas sugestões aportadas.

\section{REFERÊNCIAS}

AGRAALIMENTATION, n. 2040, 13 Novembre, p. 35-36, 2008.

BALLION, H.R. Les répresentions sociales de la montagne. In: SUPERVIVENCIA DE LA MONTAÑA/SURVIE DE LA MONTAGNE - ACTES DU COLLOQUE FRANCO-ESPAGNOL SUR L'ESPACE MONTAGNARD), 1., 1981, Madrid. Anais... Madrid: Servicio de Publicaciones Agrarias, 1981.

BARJOLLE, D.; BOISSEAUX, S.; DUFOUR, M. Le lien au terroir - Bilan des travaux de recherche. Institut d'Economie Rurale - ETHZ, 1998. Disponível em: http://www.aoc-

igp.ch/files/upload/Lien\%20\%20terroir.pdf. Acesso em: 28 nov. 2014.

BERGES-SENNOU, F.; CAPRICE, S. Les rapports producteurs-distributeurs : fondements et implications de la puissance d'achat. Economie Rurale, n. 277/278, Septembre-decembre, p. 03-16, 2003.

BERGES-SENNOU, F.; MONIER-DILHAN, S.; OROZCO, V. Les marques de distributeurs : une stratégie d'enseigne gagnante. INRA Sciences Sociales - Recherche en Economie et Sociologie Rurales, n. 5/6, Novembre, p. 01-04, 2006.

BOZONNET, J.P. Homo montivagus saisi par la publicité. Revue de Géographie Alpine, v. 79, n. 4, p. 105-117, 1991.

BRETON, P. Les Marques de distributeurs: Les MDD ne sont pas que des copies !. Paris: Dunod, 2004.

CODRON, J.M.; GIRAUD-HERAUD, E.; SOLER, L.G. Nouvelles stratégies de la grande distribution dans le secteur alimentaire. Revue Française de Marketing, n. 203, p. 3-5, Juillet 2005.

COLLA, E. Le contrepouvoir de la distribution : une synthèse des théories économiques, stratégiques et de marketing de canaux. In: ACTES DE LA $1{ }^{\text {ERE }}$ JOURNEE DE RECHERCHE RELATIONS ENTRE INDUSTRIE ET GRANDE DISTRIBUTION ALIMENTAIRE COMINDUS, 1., 2007, Avignon. Anais... Avignon: Université d'Avignon, 2007.

COLLETIS, G. et al. Firmes et territoires: entre nomadisme et ancrage. Espaces \& Société, n. 88-89, p. 115-137, 1997.

DRANCOURT, M. Les nouvelles frontières de l'entreprise : entreprise, territoire et mondialisation. Paris: Presses Universitaires de France, 2005.

FERRIER, C. Bottled water: understanding a social phenomenon. Ambio/Royal Swedish Academy of Sciences, vol. 30, n. 1, p. 118-119, 2001.

FONTGUYON, G.; GIRAUD-HERAUD, E.; ROUACHED, L.; SOLER, L. G. Qualité des produits alimentaires et marques de filières. Sociologie du Travail, vol. 45, p. 77-94, 2003.

FORT, F.; FORT, F. Alternatives marketing pour les produits de terroir. Revue Française de Gestion, n. 32, vol. 162, p. 145-159, 2006.

HASSAN, D.; MONIER-DILHAN, S. National brands and store brands competition through public quality labels. Cahier de Recherche INRA - Unité d'Economie et Sociologie Rurales, n. 09, 2004.

KAISCH, S; GILAD, B. Characteristics of opportunities search of entrepreneurs versus executives: sources, interests, general alertness. Journal of Business Venturing, vol. 6, n. 1, p. 45-61, 1991.

LAPOULE, P. Les compétences à l'origine du succès des marques de terroir des distributeurs. In: ACTES DE LA $1^{\text {ERE }}$ JOURNEE DE RECHERCHE RELATIONS ENTRE INDUSTRIE ET GRANDE DISTRIBUTION ALIMENTAIRE COMINDUS, 1., 2007, Avignon. Anais... Avignon: Université d'Avignon, 2007.

LAPOULE, P.; MENVIELLE, W. Le terroir, voie de différenciation et source de valeur ajoutée. In: ACTES DE LA JOURNEE AFM DU MARKETING AGROALIMENTAIRE A MONTPELLIER, 4., 2008, Montpellier. Anais... Montpellier : Montpellier SupAgro, 2008.

LINIGER, H.; WEINGARTNER, R. Montagnes et approvisionnement en eau douce. Revue internationale des forêts et des industries forestières - FAO, Roma, vol. 4, n. 49, 1998. Disponível em: 
http://www.fao.org/docrep/w9300f/w9300f07.htm. Acesso em: de 28 nov. 2014.

LORINO, P. ; TARONDEAU, J.C. De la stratégie aux processus stratégiques. Revue Française de Gestion, vol. 32, n. 160, p. 307-328, 2006.

MAGALI, J. Le Capital-marque des marques de distributeurs : une approche conceptuelle differenciée. Revue Française du Marketing, n. 221, vol. 1, p. 4761, 2009.

MESSEGHEM, K. Les voies de coopération entre PME et grande distribution. In : ACTES DU $7^{\circ}$ CONGRES INTERNATIONAL FRANCOPHONE EN

ENTREPRENEURIAT ET PME, 7., 2006, Montpellier. Anais... Montpellier : Association Internationale de Recherche en Entrepreneuriat et PME, 2004.

MESSEGHEM, K. Les distributeurs en quête de légitimité : le cas des accords de coopération avec les PME. Décisions Marketing, n. 39, p. 21-32, 2005.

MESSEGHEM, K. L'entrepreneuriat en quête de paradime : apport de l'école autrichienne. In: ACTES DU CONGRES INTERNATIONAL FRANCOPHONE EN ENTREPRENEURIAT ET PME, 8., 2006, Fribourg. Anais... Fribourg: Haute Ecole de Gestion, 2006.

MOATI, P. Mutations de la grande distribution et évolution de la localisation du commerce. In: TORRE, A.; FILIPPI, M. (Org.). Proximités et changements socio-économiques dans les mondes ruraux. Paris: INRA, 2005. p. 40-57.

MOREAU, B. Vague à l'âme. Rayon Boisson, n. 150, Mars, p. 67-79, 2007.

MOREAU, B.; CLAPHMAN, N. Marché sous haute tension. Rayon Boisson, n. 39, p. 74, Mars 2006.

OLSON, E. Bottled water: pure drink or pure hype? Natural Resource Defence Council (NRDC) Report. 1999. Disponível em:

www.nrdc.org/water/drinking/bw/bwinx.asp. Acesso em: 01 nov 2014.

OPEL, A. Constructing purity: bottled water and the commodification of nature. Journal of American Culture, vol. 22, n. 4, p. 67-76, 1999.

PORTER, M. L'avantage concurrentiel. Paris: Dunod, 1999.

RAYON BOISSON. Parts de marché des marques d'eaux plates nature en GMS [EM]. Rayon Boisson. [on line], 2012. Disponível em: < http://www.rayonboissons.com/Boissons-sans-alcool-et-Eaux/Parts-de-
marche-des-marques-d-eaux-plates-nature-en-GMS20596. >

RÉGNIER, F.; LHUISSER, A.; GOJARD, S. Sociologie de l'alimentation. Paris: La Découverte, 2006.

SHANE, S.; VENKATARAMAN, S. The promise of entrepreneurship as a field of research. Academic of Management Review, vol. 25, n. 1, p. 217-226, 2000.

SILVEIRA, S.C.L.; ROQUETE, R.P.L.; OLIVEIRA, L.H. Desenho e Análise da Cadeia de Valor da Água Mineral no Brasil. In: CONGRESSO DE GESTÃO DE TECNOLOGIA LATINO-IBEROAMERICANO, 15. 2013, Porto. Anais... Porto: INESC Porto, 2013.

STEVENSON, H.H.; JARILLO, J.C. A paradigm of entrepreneurship: entrepreneurial management.

Strategic Management Journal, vol. 11, p. 17-27, 1990.

VALSESCHINI, E. La dénomination d'origine comme signal de qualité crédible. Revue d'Economie Régionale et Urbaine, 2000, n. 3, p. 489-500.

VALT, R.B.G. Análise do ciclo de vida de embalagens de PET, de alumínio e de vidro para refrigerantes no Brasil variando a taxa de reciclagem dos materiais. 193 p. 2004. Dissertação (Mestrado) - Programa de Pós-graduação em Engenharia, Universidade Federal do Paraná. Curitiba, 2004

VAZQUEZ-BARQUERO, A. Desenvolvimento endógeno em tempos de globalização. Porto Alegre: UFRGS; Fundação de Economia e Estatística, 2002.

VERSTRAETE, T. Essai sur la singularité de l'entrepreneuriat comme domaine de recherche. Paris: Les édition de l'ADREG, 2002.

VERSTRAETE, T.; FAYOLLE, A. Paradigmes et entrepreuneuriat. Revue de l'Entrepreneuriat, vol. 4, n.1, p. 33-52, 2005.

WILK, R. Bottled water: the pure commodity in the age of branding. Journal of Consumer Culture, vol. 6, n. 3, p. 303-325, 2006.

ZAHRA, S. A.; KORRI, J. S.; YU, J.F. Cognition and international entrepreneurship: implications for research on international opportunity recognition and exploitation. International Business Review, vol. 14, n. 2, p. 129-146, 2005. 